\title{
HOW INFORMATIONAL INJUSTICE LEADS TO EXIT INTENTIONS: CYNICISM IN HIGHLY IDENTIFIED EMPLOYEES
}

\author{
DAVID PATIENT \\ UCP - Católica Lisbon School of Business and Economics \\ Palma de Cima, 1649-023 Lisbon, Portugal \\ FRANCESCO SGUERA \\ UCP - Católica Lisbon School of Business and Economics \\ MARJO-RIITTA DIEHL \\ EBS Business School
}

INTRODUCTION

Employees are often skeptical about major organizational change, in terms of doubting whether initiatives will achieve their stated objectives (Stanley, Meyer, \& Topolnytsky, 2005). Beyond that, employees are often cynical, defined as disbelieving the stated or implied reasons for change initiatives (Stanley et al., 2005). Employee cynicism can be a serious obstacle to successful change because it involves a loss of faith in the stated motives and sincere communication of leaders. Though widespread (Dean, Brandes, \& Dharwadkar, 1998;1998; Reichers, Wanous \& Austin, 1997), employee cynicism has received relatively little scholarly attention (Brandes, Castro, James, Martinez, Matherly, Ferris, \& Hochwarter 2008). Its antecedents and consequences merit further attention, especially in the context of major changes, such as layoffs, where employee resistance is likely to be substantial.

An important predictor of employee reactions to organizational change initiatives is the timing, quality, and perceived sincerity of explanations received, referred to as informational justice (Colquitt, Conlon, Wesson, Porter \& Ng, 2001). At times of change employees pay increased attention to fairness (Fugate, Prussia, \& Kinicki, 2012; Kernan \& Hanges, 2002). As employees seek to understand how they will be affected by the changes, the timeliness and adequacy of explanations provided by the organization (i.e., informational justice) become especially important. On the other hand, informational justice might not be equally effective at all times in reducing cynicism regarding organizational change, For example, previous research indicates that employees who identify strongly with their organization react differently to those with low organizational identification, in particular during negative events (Wiesenfeld, Brockner, \& Thibault, 2000)).

In this research, we focus on informational justice and cynicism in the context of a particularly jarring type of change: downsizing and layoffs. Specifically we investigate whether employee cynicism mediates the effect of informational justice on intentions to voluntarily leave their organization. In addition, we propose that informational justice will be more important to employees that identify highly with their organization. We are among the first to directly examine the relationship between organizational justice and employee cynicism. Whereas prior research on survivor fairness perceptions in layoff situations has focused on procedures by which change was implemented (procedural justice), we focus on the way in which it was communicated (informational justice). In investigating cynicism as a possible mediator of the effects of informational justice on exit intentions, we explore an important mechanism as to why 
informational injustice can lead to negative employee reactions. Finally, we test an important boundary condition influencing the importance of informational justice to employee cynicism and exit intentions: high versus low levels of organizational identification.

Insert Figure 1 about here

We test our hypotheses in three studies. Study 1 and Study 2 use diverse samples of US employees and a scenario exercise in which variables of interest are manipulated. In Study 3, a questionnaire was administered to 1821 employees in a European organization undergoing a major restructuring which included layoffs.

\section{THEORY AND HYPOTHESES}

\section{Informational Justice and Employee Cynicism}

Although some research has conceptualized organizational cynicism as an attitude composed of beliefs, affect, and behavioral tendencies toward an organization (Dean, Brandes \& Dharwadkar, 1998), we follow Stanley and colleagues (2005) in focusing on the cognitive component of cynical attitudes. In particular, we believe beliefs regarding target motives distinguish employee cynicism from related constructs, such as skepticism or trust.

A substantial literature supports the existence of four different justice types, relating to: equitable outcomes (distributive), procedures (procedural), respect and concern (interpersonal), and adequacy of explanations (informational). We focus in this research on the informational dimension of justice. First, its effects on employee reactions have received less research attention than procedural justice. Second, informational justice is especially important when a change initiative necessitates substantial involvement of direct supervisors (Rodell \& Colquit, 2009). There are several reasons why informational justice regarding organizational layoffs may relate to survivor cynicism. Organizational justice is more important at times of uncertainty and when people are acutely reminded about the fragility of some important aspect of their lives (Van den Bos, 2001). By providing justifications, excuses, or apologies an organization can show that they have reasonable and sincere motives. Stanley and colleagues (2005) found that communication of reasons for change reduced employee cynicism, and Schweiger and DeNisi (1991) identified inadequate communication as one of the factors most likely to lead to cynicism.

Hypothesis 1: Employee informational justice perceptions regarding an organizational change relate negatively to employee cynicism.

\section{Cynicism and Exit Intentions}

Cynical employees tend to view their organizations with suspicion, to believe the organization will be exploitative, and to doubt the positive reasons provided for change initiatives (Andersson \& Bateman, 1997). Cynicism relates to emotional exhaustion and burnout (Maslach, Schaufeli, \& Leiter, 2001), job dissatisfaction, absences (Johnson \& O'Leary-Kelly, 2003), distrust (Pugh, Skarlicki \& Passell, 2003), grievances (Reichers et al., 1997), and lower levels of commitment and motivation. Stanley and colleagues (2005) found that cynicism relates 
to employee intentions to resist change. Likewise, Wanous and colleagues (2000) showed that cynicism influences negatively employees' motivation to support and continue with change efforts. Overall, cynicism involves heightened attention to the negative (Leung, Ip \& Leung, 2010). Therefore, it is no surprise that Burke (2004: 279-280, italics added) describes layoff survivors to suffer from a syndrome characterized by a "constellation of negative attitudes and behaviors, including low morale, diminished commitment, heightened cynicism, mistrust, and increased anger". For the above reasons, we expect more (versus less) cynical survivors to have higher intentions to leave their organization. Thus,

Hypothesis 2: Employee cynicism regarding organizational change will mediate the negative relationship between employee informational justice perceptions and exit intentions.

\section{The Moderating Effect of Organizational Identification}

We propose that organizational identification moderates the mediated relationship from informational justice to exit intentions via cynicism. We have argued that informational justice reduces employees' exit intentions and that this effect occurs through reduced levels of cynicism. This might especially be the case for employees with strong level of organizational identification. First, organizational identification makes employees more intensively experience the successes and failures of the organization (Pratt, 1998). Second, following relational models of justice (e.g., Lind \& Tyler, 1992), because of its effects on feelings of status and inclusion, informational justice should be more important to employees who identify strongly with the organization. In summary, we propose a moderated mediation model in which organizational identification moderates the indirect effect of informational justice on employee exit intentions (via employee cynicism).

Hypothesis 3: The indirect relationship between informational justice and exit intentions via anticipatory employee cynicism will be stronger when employees have high organizational identification.

\section{STUDY 1}

Study 1 was used to test the mediational effect of cynicism on the relationship between manipulated informational (in)justice and exit intentions. One hundred and forty-seven US workers were recruited through an online web-based platform to participate in a scenario experiment. Participants read a scenario regarding a crisis faced by an organization and were asked to put themselves in the position of an employee. Participants are told that their company will reduce wages and lay off some employees. Participants were randomly assigned to high/ low informational justice conditions. Validated scales were used to measure cynicism towards the organization (Pugh et al., 2003), exit intentions (Rusbult et al., 1988), and, as a manipulation check, informational justice (Colquitt, 2001). We controlled for participant work experience, gender, education, and age. Participants who read the low informational justice scenario (i.e., injustice) rated informational justice as significantly lower than those who read the high informational justice scenario. Using hierarchical regressions and the bootstrapping method for 
testing indirect effects, the direct effect of manipulated informational (in)justice on cynicism was positive and significant, while the direct effect of manipulated informational (in)justice on exit intentions was not significant. Further, the effect of cynicism on exit intentions was positive and significant. The coefficient for the indirect effect of informational (in)justice on exit intentions through cynicism was .06 , and the $95 \%$ bias-corrected confidence interval ranged from $\mathrm{LLCI}=.003$ to $\mathrm{ULCI}=.163$ (5,000 bootstrap resamples). Because this confidence interval does not include zero, the mediation test is statistically significant at a level of .05. Therefore, we can conclude that the relationship between informational (in)justice and exit intentions is mediated by cynicism, providing support for Hypothesis 1 and Hypothesis 2.

\section{STUDY 2}

The goal of Study 2 was to corroborate the mediational findings of Study 1 under a specific boundary condition: organizational identification of the employee. Study 2 was a scenario experiment in which 78 participants were randomly assigned to one of four experimental conditions: high/low informational (in)justice and high/low organizational identification. Participants read the same scenario as in Study 1. In addition some of them read that they were highly identified with their organization, whereas others read that they did not identify with the organization. We used the same measures as in Study 1.

We tested the hypotheses regarding the moderating effects of organizational identification on the influence of informational (in)justice on exit intentions (via cynicism) following the procedure for moderated mediation regression analysis outlined by Preacher and colleagues (2007) and Hayes (2013). The interaction between informational (in)justice and organizational identification was a significant predictor of our mediator cynicism $\left(b=.34, p<.05 ; \Delta R^{2}=.05\right)$. In support of our moderated mediation model, the coefficient for the indirect effect of informational (in)justice on exit intentions through cynicism at high levels of organizational identification was positive and significant $(b=.43$, BootLLCI $=.176$ and BootULCI $=.802)$, whereas the indirect effect at low levels of organizational identification was not significant $(b=.14, p<.001$; BootLLCI $=-.210$ and BootULCI $=.316$; confidence intervals include zero).

Thus Hypotheses 1, 2, and 3 were all supported.

\section{STUDY 3}

In Study 3 we tested test our hypotheses in a real change situation. An electronic questionnaire was sent to 4000 employees of the Finnish subsidiary of a large telecom services provider that had conducted multiple rounds of layoffs. The final sample consisted of 1821 employees. The survey was administered in Finnish. Informational justice was measured with two items adapted from Colquitt (2001) and two items developed for this context. Cynicism was measured using four items (Organizational Cynicism Scale, Pugh et al., 2003). To measure organizational identification, we used three items from Smidts, Pruyn, and van Riel (2001). Exit intentions was measured using two items from Rusbult and colleagues (1988). Gender, age, tenure, and education were controlled.A confirmatory factor analysis showed that the model fits the data well and better than alternative CFA models, thus exhibiting satisfactory discriminant validity for our measures. As in Study 2, we tested the hypotheses regarding the moderating effects of organizational identification on the relationship between informational justice, cynicism and exit intentions following the procedure for moderated mediation regression 
analysis. However, this time informational justice and organizational identification were measured, rather than manipulated.

Results indicate that the interaction between informational (in)justice and organizational identification was a significant predictor of our mediator cynicism $\left(b=.07, p<.05 ; \Delta R^{2}=.003\right)$. Simple slope analyses indicated that for employees with high organizational identification, the association between informational (in)justice and cynicism was positive, significant, and higher (+ 1 S.D.; $b=.35, p<.001$; see Figure 3 ), compared to employees with low organizational identification ( 1 S.D.; $b=.24, p<.001$ ) Next, we investigate the mediating role of cynicism on the relationship between informational (in)justice and exit intentions. As shown in the outcome model, the effect of cynicism on exit intentions is positive and significant $(b=.60, p<.001)$, whereas informational (in)justice has no direct effect on exit intentions $(b=.04, n s)$.In support of our moderated mediation model, the coefficient for the indirect effect of informational (in)justice on exit intentions through cynicism at high levels of organizational identification was significant and higher ( +1 S.D.; $b=.21, p<.001$; BootLLCI=.1606 and BootULCI $=.2542)$ than the indirect effect at low levels of organizational identification (- 1 S.D.; $b=.14, p<.001$; BootLLCI $=.0945$ and BootULCI $=.1865)$. Thus, all hypotheses were confirmed.

\section{GENERAL DISCUSSION}

This study extends investigations into an under-researched but prevalent phenomenon: employee cynicism, with an attempt to broaden the theoretical and empirical basis of cynicism research with organizational justice. Cynicism, on the whole and specifically relating to layoffs, has received relatively little research attention despite the fact that the number of survivors and direct victims of layoffs continues to increase (Paulsen et al., 2005). Given its influence on resistance to change (Stanley et al, 2005), further work on causes and effects employee cynicism is warranted (Andersson, 1996; Dean et al., 1998). By demonstrating the effects of informational justice and organizational identification on cynicism and exit intetnions during layoffs, this research addresses calls for investigations relating cynicism to specific organizational characteristics and managerial practices (Andersson \& Bateman, 1997). Our hypotheses were confirmed using different samples and methodologies. Study 1 and Study 2 manipulated employee informational justice in a scenario that ensured participants in each condition responded to the same situation, and that other differences among conditions were controlled for. The samples in both Study 1 and Study 2 were diverse groups of US employees recruited online for paid participation. The sample in Study 3 was from a European organization, and consisted of employees who responded to questions regarding a real organizational change situation involving layoffs that they had observed in their own organization. The replication of the mediation (whereby the effect of informational (in)justice on exit intentions was channeled through employee cynicism) in all three studies, and the replication of the moderation (whereby the effect of informational (in)justice on cynicism was greater for employees who identified highly with their organization) gives us confidence in the findings.

\section{CONCLUSION}

As major organizational changes are increasingly the norm, improving our understanding of employee reactions to such changes becomes paramount (Fedor, Caldwell \& Herold, 2006). Employee cynicism is an unfortunate but common reaction to major organizational change, 
including layoffs. Fortunately, our findings suggest that survivors' cynical attitudes can be reduced by informational justice in terms of accurate and timely information about organizational change efforts, in particular among employees who identify highly with their organization. Therefore, organizational communication regarding change should specifically target - and certainly not overlook - employees with a strong organizational identity.

\section{REFERENCES AVAILABLE FROM THE AUTHORS}

\section{FIGURE 1}

Theoretical Model

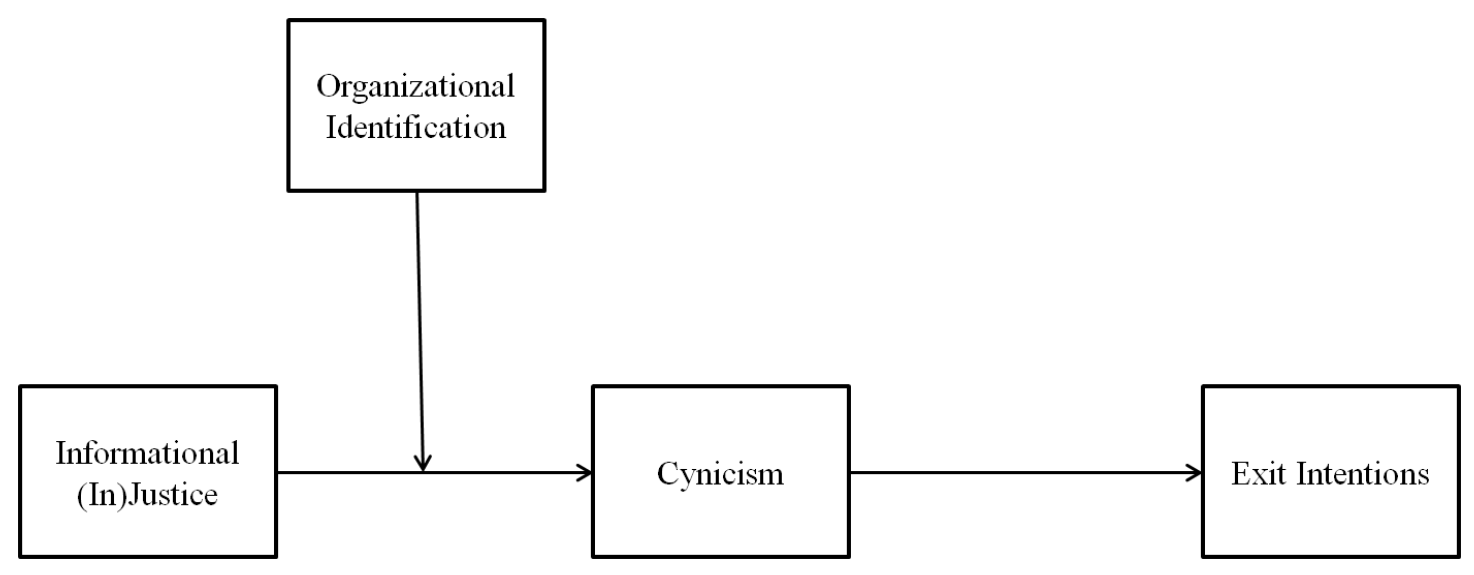

